eISSN 2444-7986

DOI: https://doi.org/10.14201/orl201781.15663

\title{
Editorial
}

\section{ANCLADOS EN EL FUTURO}

\section{Anchored in the future}

\author{
José Luis PARDAL-REFOYO \\ Director de Revista ORL \\ Correspondencia: jlpardal@usal.es
}

Fecha de publicación: 23 de enero de 2017

Fecha de publicación del fascículo: 1 de marzo de 2017

Conflicto de intereses: Los autores declaran no tener conflictos de intereses

Imágenes: Los autores declaran haber obtenido las imágenes con el permiso de los pacientes

Política de derechos y autoarchivo: se permite el autoarchivo de la versión post-print (SHERPA/RoMEO)

Licencia CC BY-NC-ND. Licencia Creative Commons Atribución-NoComercial-SinDerivar 4.0 Internacional

(c) Universidad de Salamanca. Su comercialización está sujeta al permiso del editor

Hasta hace un momento daba por perdidas mis anotaciones sobre esta carta. Así echaba de menos la época del cuaderno y de las notas escritas en el papel. Hoy estamos rodeados de dispositivos y esto nos hace vulnerables. No voy a entrar más que en esta superficie bajo la cual hay mucho sobre lo que hablar y sobre lo que cada uno tendrá su opinión. Las notas aparecieron en un fichero de mi tableta que, simplemente, había cambiado de lugar entre los miles de documentos que almaceno. Un simple cambio que puede hacer del documento un desaparecido porque, entre las prisas, no había recibido el nombre correcto. He aquí un ejemplo de la vulnerabilidad de la que hablo y como un documento puede ser invisible. Este temor a la pérdida nos lleva a la compulsiva necesidad de hacer copias y más copias de seguridad. Nada más inseguro. Un cambio en el soporte, en los programas o en los sistemas de reproducción y la copia también pasará a ese mundo de los perdidos en el que se encontrarán, pienso, millones de documentos y de información sin nadie a quien poder informar, olvidados. Este es uno de los muchos riesgos de la documentación que generamos, que las generaciones futuras pierdan los códigos y no hallen su «piedra de Rosetta» para descifrar los contenidos y nos olviden.

Para evitar el olvido seguimos nuestros rituales, y tal vez el más hermoso sea el de comunicarnos, así también nos recordamos. $Y$ otros buscan, investigan el pasado y al comunicar, recuerdan, sacan del olvido y hacen presente a aquéllos cuyas huellas aún perduran.

Uno de los objetivos permanentes de cualquier medio de comunicación es obtener la máxima visibilidad, llegar al mayor número de personas a las que potencialmente pueda interesarles la información publicada.

El 6 de diciembre recibimos la noticia de que Revista ORL había sido incluida en el Emerging Source Citation Index - ESCl- de la Web of Science -WoS- solicitada tan solo 
unas semanas antes, antesala del tan codiciado Journal Citation Reports - JCR- [1, 2]. Un premio al esfuerzo de estos meses que nos ayuda, sin duda, a seguir trabajando por conseguir que Revista ORL vaya mejorando su posición progresivamente en las bases de datos biomédicas (IBECS, SciELO, Medline). En ESCl ya están otras revistas del grupo Ediciones Universidad de Salamanca (EUSAL): "América Latina Hoy», "Zephyrus», y «Fonseca. Journal of Communication» [3-6].

El 13 de diciembre de 2016 el centro de atención estuvo en la revista «Studia Historica. Historia Antigua», dirigida por el Profesor Manuel Salinas de Frías, por la obtención del sello de calidad FECYT [7, 8]. La satisfacción de veía en su rostro, se entendía en sus palabras y estaba en todos los presentes [9]. Además, renovaron su sello FECYT otras cuatro revistas editadas por EUSAL: «América Latina Hoy», "Studia Historica. Historia Moderna», "Teoría de la Educación. Revista Interuniversitaria» y «Zephyrus». [3, 4, 10, 11]. Revista ORL va por su misma senda para conseguir el reconocimiento del sello de calidad que significa FECYT.

Dice alguien que conoce bien la actividad de Revista ORL, y que por amor a su trabajo le da color, que "ORL es más que una revista» [12]. Y así es, «... es una zona de ocio, de creatividad...», "... una oportunidad para disfrutar comunicando» [13]. Revista ORL es «... de acceso restringido a quienes quieran comunicar disfrutando» [12]. Y este espíritu es el que debe prevalecer, porque la consecución de los objetivos vendrá sola. Hay muchas revistas, pero una de las características del universo es paradójicamente la diversidad en cualquier área en la que nos fijemos (cosmológica, biológica, social) y justamente la pérdida de esa diversidad conduce a la extinción del sistema. Por tanto, la diversidad es una fortaleza.

En noviembre de 2016 tuvimos la oportunidad de asistir al "Curso de certificación XML JATS» ofrecido por Redalyc [14]. Los editores de EUSAL mantienen un esfuerzo continuo para mejorar la visibilidad de las publicaciones y cumplir los protocolos de interoperatividad. Actualmente el lector es un usuario web y las revistas deben aprovechar ese potencial para situarse (conexión de información, conocimiento, inteligencia, personas), por ello nos acercaremos a la marcación XML tan necesa- ria para estar en las bases de datos biomédicas.

Todo esto significa una voluntad común en la que editores, autores y revisores están implicados. El editor desea ofrecer un producto que facilite la publicación de los informes de investigación y el autor desea que su informe sea publicado, visible para quienes deseen utilizarlo y, si es posible, recuperar el esfuerzo en forma de citación por parte de otros autores. Este aspecto, el de la citación, va a depender de muchos factores. Unos relacionados con la visibilidad (que la información se encuentre donde los lectores esperan encontrarla) y otros relacionados con la calidad del informe de investigación. Ambos se relacionan y se retroalimentan. Por eso, pese a las dificultades, estos son los objetivos, mejorar la visibilidad con herramientas como son el esfuerzo, la internacionalización y la mejora de la gestión editorial.

No quiero profundizar sino trazar líneas que creen inquietud en quienes lean este editorial. Recomiendo la lectura de las reflexiones de Lorenzo García Aretio que las creo muy acertadas y me identifico con ellas [15].

La actividad de los editores y revisores debe ser incluida en los curricula. Entre los muchos errores que se heredan y contra los que hemos de luchar los editores en lengua española está el de mirar hacia otro lado, exclusivamente evaluando y premiando el papel de autor que ve su trabajo publicado (todos lo somos en algún momento), olvidando que los informes de investigación, sean o no publicados, generan conocimiento y precisan esfuerzo editorial.

La actividad editorial tiene su aspecto de monotonía. Los plazos, los formalismos, las normas, las decisiones difíciles, pero tiene mucho de actividad creativa en la planificación. Esa es la compensación, el gusto por facilitar la publicación. Tenemos claras referencias de los mejores para seguir las mejores prácticas editoriales y dar el salto a las plataformas más especializadas.

Dice Eduardo Anitua que los soñadores viven anclados en el futuro [16]. Y así debe ser. Desde los editoriales hemos apelado a la responsabilidad, al esfuerzo, al trabajo... [17] y no puede ser de otro modo, ningún proyecto se materializa sin ellos. 
Ponemos nuestra mirada en el futuro, camino y residencia de los soñadores con nuestras herramientas, la «hoja y el lápiz para un oído limpio, curioso y desconfiado» [18].

Como siempre os doy las gracias y deseo a todos los que colaboráis con Revista $O R L$, un provechoso año 2017.

\section{REFERENCIAS}

1. Web of Science. Disponible en: https://apps.webofknowledge.com/. [Citado el 22 de enero de 2017].

2. Journal Citation Reports. Disponible en: https://incites.thomsonreuters.com/. [Citado el 22 de enero de 2017].

3. América Latina Hoy. Disponible en Http://revistas.usal.es/index.php/1130-2887/ index. [Citado el 22 de enero de 2017].

4. Zephyrus. Disponible en http://revistas.usal.es/index.php/1130-2887/ index. [Citado el 22 de enero de 2017].

5. Fonseca. Joumal of Communication. Disponible

en: http://revistas.usal.es/index.php/2172-9077/ index. [Citado el 22 de enero de 2017].

6. Ediciones Universidad de Salamanca. Disponible en: Http://www.eusal.es/. [Citado el 22 de enero de 2017].

7. Studia Historica. Historia Antigua. Disponible en: http://revistas.usal.es/ index.php/0213-2052/index. [Citado el 22 de enero de 2017].

8. FECYT. Fundación Española para la Ciencia y la Tecnología. Disponible en: https://www.fecyt.es/. [Citado el 22 de enero de 2017].

9. Comunicación Universidad de Salamanca. La revista 'Studia Historica. Historia Antigua' publicada por Ediciones Universidad de Salamanca recibe el sello de calidad FECYT. 13/12/2016. Disponible en: http:// saladeprensa.usal.es/node/104657. [Citado el 22 de enero de 2017].
10. Studia Historica. Historia Moderna. Disponible en: http://revistas.usal.es/index.php/1130-2887/ index. [Citado el 22 de enero de 2017].

11. Teoría de la Educación. Revista Interuniversitaria. Disponible en: http://revistas.usal.es/index.php/1130-2887/ index. [Citado el 22 de enero de 2017].

12. El cuaderno de Martinde. Lo que queda del día. "ORL es más que una revista". 29 de diciembre de 2016. Disponible en: http://www.martinde.com/2016/12/ORLrevista-Otorrinolaringologia.html?m=1. [Citado el 22 de enero de 2017].

13. Revista ORL. Facebook. 6 de enero de $2017 . \quad$ Disponible en: https://www.facebook.com/revistaorl/?ref=b ookmarks. [Citado el 22 de enero de 2017].

14. Redalyc. Curso de certificación XML JATS. Disponible en: https://xmljatsredalyc.org/category/curso-decertificacion-xml-jats/. [Citado el 22 de enero de 2017].

15. García Aretio L. Publicar (casi exclusivamente) en revistas de impacto. Ried. 2015;18(2):7-22. Disponible en: https://doi.org/10.5944/ried.18.2.14254. [Citado el 22 de enero de 2017].

16. Pepa Fernández. No es un día cualquiera. Entrevista a Eduardo Anitua. 3 de julio de 2016. Radio Nacional de España. Disponible en: http://mvod.Ivlt.rtve.es/resources/TE SNOE SEN/mp3/8/4/1467540257448.mp3. [Citado el 22 de enero de 2017].

17. Pardal-Refoyo JL. Hoja y lápiz para un oído limpio. Revista ORL. 2017;7(1):1-3. Disponible en: http://dx.doi.org/10.14201/orl201671.13563. [Citado el 22 de enero de 2017].

18. Ida Vitale. HOJAS NATURALES. Todo de pronto es nada. XXIV Premio Reina Sofía de Poesía Iberoamericana. Ediciones Universidad de Salamanca / Patrimonio Nacional. 2015. P. 285. 